\title{
Balancing risk versus benefit: the elderly patient's perspective on warfarin therapy
}

\author{
Beata V. BAJOREK, Susan J. OGLE, Margaret J. DUGUID, Gillian M. SHENFIELD, Ines KRASS.
}

\author{
Received (first version): 8-Jan-2009 Accepted: 6-May-2009
}

\begin{abstract}
*
Warfarin therapy is underused in the target at-risk elderly population. Clinicians perceive that older patients are reluctant to use this therapy, however the perspective of patients or their carers has yet to be explored.

Objective: To explore in-depth the perspectives of elderly patients and/or their carers regarding the use of warfarin therapy.

Method: A qualitative study, using semi-structured group interviews was undertaken. The audio-taped discussions were transcribed verbatim, then thematically analysed to identify emergent themes. Group discussions were conducted at a major Sydney teaching hospital, over a 2-month period. Individuals aged 65 years or older (and/or their carers) who were using long-term ( 6 months) warfarin therapy were recruited by voluntary response to study flyers.

Results: 17 patients and carers (mean age 77.2 $\mathrm{SD}=7.5$ years) participated in one of two focus groups. Five core themes emerged regarding warfarin therapy: inadequate knowledge and understanding about it, patients/carers variable experience of information provision, cycle of reactions to being on it, issues in its practical management, and the spectrum of experiences with it. Overall, participants were very accepting of the therapy, describing a high level of compliance, despite initial fears and anxieties, and a relative lack of knowledge. Patients felt somewhat abandoned in their management of warfarin due to the lack of ongoing support services in the community, and inadequate information provision.

Conclusions: Elderly patients and their carers appear to be quite accepting of warfarin therapy, in contrast to the perceptions of health care professionals. More effort is needed, however, in
\end{abstract}

\footnotetext{
Beata V. BAJOREK. BPharm, DipHPharm, PhD. Lecturer in Pharmacy. Research Associate, Clinical Pharmacology and Aged Care \& Rehabilitation, Royal North Shore Hospital. Faculty of Pharmacy, University of Sydney (Australia).

Susan J. OGLE. MBBS, FRACP. Clinical Senior Lecturer in Medicine. Head Aged Care \& Rehabilitation Medicine. Department of Aged Care and Rehabilitation, Royal North Shore Hospital. St Leonards (Australia)

Margaret J. DUGUID. BPharm. Former Head Department of Pharmacy, Royal North Shore Hospital. St Leonards (Australia).

Gillian M. SHENFIELD, DM, FRCP, FRACP. Former Head Department of Clinical Pharmacology. Royal North Shore Hospital. St Leonards (Australia).

Ines KRASS. BPharm, DipHPharm, PhD. Head of

Department, Pharmacy Practice, Faculty of Pharmacy, University of Sydney (Australia).
}

terms of information provision, particularly in the form of community-based services, to assist patients in the long-term management of warfarin.

Keywords: Warfarin. Attitude to Health. Aged. Qualitative Research. Australia.

\section{SOPESANDO RIESGO Y BENEFICIO: PERSPECTIVA DEL PACIENTE ANCIANO A TRATAMIENTO CON WARFARINA}

\section{RESUMEN}

El tratamiento con warfarina se sub-utiliza en los ancianos de alto riesgo. Los clínicos perciben que los ancianos son reacios a este tratamiento, sin embargo la perspectiva de los pacientes y de sus cuidadores aún no ha sido estudiada.

Objetivo: Explorar en profundidad las perspectivas de los pacientes ancianos y/0 sus cuidadores sobre el uso de tratamiento con warfarina.

Método: Se realizó un estudio cualitativo, utilizando entrevista semi-estructurada en grupos. Las discusiones grabadas se transcribieron a papel, y se analizaron temáticamente para identificar los temas emergentes. Las discusiones en grupos se realizaron en un gran hospital universitario de Sydney durante un periodo de dos meses. Mediante respuesta voluntaria a folletos, se reclutó a individuos de 65 o más años (y/0 sus cuidadores) que estaban utilizando crónicamente (6 o más meses) tratamiento con warfarina.

Resultados: 17 pacientes y cuidadores (edad media $77,2 \mathrm{DE}=7,5$ años) participaron en uno de los dos grupos focales. Emergieron 5 temas principales en lrelación al tratamiento con warfarina: conocimiento y entendimiento inadecuado, experiencia variable de pacientes/cuidadores de la información proporcionada, ciclo de reacciones de estar bajo esto, problemas de manejo práctico, y espectro de experiencias con el tratamiento. Generalmente los participantes aceptaban bien el tratamiento, describiendo altos niveles de cumplimiento, a pesar de sus miedos y ansiedades inicial, y la relativa falta de conocimiento. Los pacientes se sentían algo abandonados en su manejo del tratamiento con warfarina debido a la falta de servicios de apoyo continuo en la comunidad y de la inadecuada provisión de información.

Conclusión: Los pacientes ancianos y sus cuidadores parecen estar tranquilos aceptando el tratamiento con warfarina, en contraste con la percepción de los profesionales de la salud. Sin embargo se necesita un mayor esfuerzo en relación 
a la provisión de información, especialmente en los servicios comunitarios, para ayudar a los pacientes en el manejo de la warfarina a largo plazo.

Palabras clave: Warfarina. Actitud hacia la salud. Ancianos. Investigación cualitativa. Australia.

\section{INTRODUCTION}

Although a potentially life-saving medication, warfarin is difficult to manage for patients and health professionals alike. This anticoagulant carries an inherent risk of excessive, and potentially lifethreatening, bleeding that is amplified by its complex pharmacology, as well as drug and food interactions. Hence, there is a very narrow range of dosages within which warfarin carries a low risk of bleeding, but is also effective in preventing clots and strokes. Achieving the optimal dose for each patient requires vigilance on both the part of the patient and the health carer, and involves regular blood testing to measure clotting time (INR, international normalised ratio), frequent dosage adjustment and careful titration, and extensive patient education.

In view of these difficulties, clinicians have been reluctant to prescribe warfarin, to the extent that it remains underutilised in high-risk patients, e.g., those with the common cardiac arrhythmia, atrial fibrillation $^{1-5}$, particularly the target elderly population. ${ }^{6}$ One key reason cited by clinicians for this suboptimal use is the perceived refusal of patients' to use, and therefore be compliant with, this complicated and potentially risky therapy. ${ }^{7-10}$ However, this notion has neither been explored nor confirmed with patients, and is in contrast to the findings reported in patient surveys. ${ }^{9-12}$

Therefore, the aim of this study was to explore indepth the issues surrounding the long-term use of warfarin from the perspective of elderly patients and/or their carers. The specific objectives were to: describe patients' and/or carers' experiences and attitudes toward the use of warfarin; explore their perceptions regarding the risks and benefits of warfarin therapy; identify any 'barriers' to the longterm use of warfarin as perceived and/or experienced by them; and investigate their perceived roles regarding warfarin therapy.

\section{METHODS}

\section{Study Design}

This qualitative study was undertaken at a major Sydney teaching hospital, over a 2-month period. Group interviews (focus groups) were conducted to draw upon the attitudes, feelings, beliefs, experiences and reactions of the participants in a way that would not be feasible using observation, one-to-one interviewing, or questionnaire surveys alone. ${ }^{13} \mathrm{~A}$ semi-structured process was used, where each discussion was moderated by a 'facilitator', cofacilitator, and scribe using a set of broad openended questions that reflected the pre-determined research objectives. Specific topics that were explored included: participants' understanding of, experiences with, and management of warfarin therapy; specific barriers to using warfarin therapy; and overall, how participants felt about being on warfarin therapy. Based on our theoretical framework (described below), sub-sets of probing questions were designed to explore issues within the discussion topics, which enabled the facilitator to promote discussion and elicit detailed responses; all questions were pre-tested in mock individual interviews with non-participants. Demographic data were collected prior to the group interviews using a specially designed questionnaire. Approval for the conduct of the study was granted by the institutional Human Research and Ethics Committee.

\section{Theoretical framework}

A conceptual model of potential issues, including biological, psychological and social aspects, surrounding warfarin use was developed (Figure 1). This was analogous to that described by an Australian study examining the biopsychosocial impact of a disease and its treatment on patients and their families. ${ }^{14}$

\section{Recruitment of Participants}

Individuals were eligible to participate in this study if they were either: 1 ) elderly (equal or over 65 years old) and were prescribed long-term (equal or over 6 months) warfarin therapy for a chronic condition such as atrial fibrillation, or 2) were the primary carer of such a patient. Recruitment of participants was by voluntary response to study flyers displayed in key locations around both the project hospital and larger community within the Northern Sydney Area Health Service, e.g., aged care, cardiology, general medicine, and neurology wards; outpatient clinics; pathology collection areas; and local community centres that provided medicine information sessions for senior citizens. Additionally, project flyers were mailed to patients who had previously expressed an interest, to the investigators, in sharing their opinions about warfarin use. Sampling was therefore largely opportunistic to capture the target population, and purposive to find patients and/or carers willing to discuss their experiences.

Participants provided their informed written consent to participate after reading the approved project information sheet, as approved by the institutional human research and ethics committee. To compensate for any losses incurred by attendance all participants were offered a nominal payment of AUD 25.00, reimbursement of travel expenses, and the provision of food and beverages. Information regarding this payment was provided upon enquiry during the recruitment stage, and was declared on the consent forms.

\section{Data collection and analysis}

Since data collection was dependant on the verbal responses of participants, each session was audiotaped. In addition, the scribe also observed and noted any non-verbal behaviour (e.g., facial expressions, body language, paralanguage etc) that reinforced any significant statements made by participants. 



Figure 1. Conceptual model of the various biopsychosocial ${ }^{\star}$ factors affecting the use of warfarin (adapted from White and Grenyer, 1999.)

Once the audio-taped discussions were transcribed verbatim, they were content-analysed to identify emergent themes. A phenomenological approach was used in this study, focussing on understanding the essence of experiences about a phenomenon via statements, meanings, themes, and general descriptions of the experience. ${ }^{15,16}$

Several measures were taken to ensure that the conclusions drawn from the analysis were valid, i.e., that they were consistent with the actual content such that the findings were grounded in data, inferences were logical, and thematic structures were legitimate. First, two of the investigators (acting as co-facilitator and scribe) observed the discussions. ${ }^{17}$ Second, these two investigators independently read through the transcripts and identified relevant themes, issues and supporting statements, before jointly discussing the findings to attain a consensus. Third, the findings were checked against the supplementary notes taken by the scribe. Fourth, the findings were reviewed by the main facilitator, as well as fed-back to some of the participants to ensure the accuracy of the session's interpretation.

\section{RESULTS}

\section{Participants}

In total, 17 individuals (14 patients and 3 carers) took part in one of two, 1-hour long, focus groups. On average, participants were $77.2(+/-7.5)$ years old (range: 65 - 91 years). The mean length of time that these participants were using (i.e., taking or administering) warfarin therapy was 6.35 years (range: 0.5 - 29 years). In all cases, warfarin therapy was prescribed for stroke prevention in atrial fibrillation; in one individual there was an additional indication for warfarin (artificial heart valves).

\section{Emergent themes}

Similar themes were identified between the two patient/carer groups, and hence the data were pooled. Overall, five core themes emerged:

1. Inadequate knowledge and understanding of warfarin therapy

2. Patients/Carers experience of information provision

3. Patient/Carer reactions to being on warfarin

4. Self-management of warfarin therapy

5. Spectrum of experiences with warfarin

Theme 1:Inadequate knowledge and understanding of warfarin therapy

Participants expressed, both consciously and subconsciously (as implied through their descriptions), a lack of understanding about warfarin, both in terms of general concepts and specific aspects of the therapy (Table 1). It was not explicitly understood that it was a long-term preventative therapy against stroke and other 'blood-clots' arising from the altered heart rhythm. However, participants knew that it was related to the overall treatment of atrial fibrillation, often associating it with the procedure of direct current cardioversion, whether successful or unsuccessful. A few believed that warfarin was an alternative to cardioversion, with some expressing a preference for either treatment. Many were also unable to relate the risk of stroke to their atrial fibrillation or other underlying condition. Only those taking warfarin for secondary stroke prevention knew its indication fully.

I want to know what happens to you, will you have a stroke or whatever it is? What am I taking it for? Participant 1 
Heart fibrillation and then the stroke comes next. Participant 2

Oh I see. Well. Participant 1

I was just told I had to take it to prevent blood clots! Participant 3
As a consequence of the lack of understanding about warfarin's purpose, there was also uncertainty about the duration of the therapy.

No ... [the doctor] said you are on it but he didn't say whether you are coming off or whether you are going to stay on it!

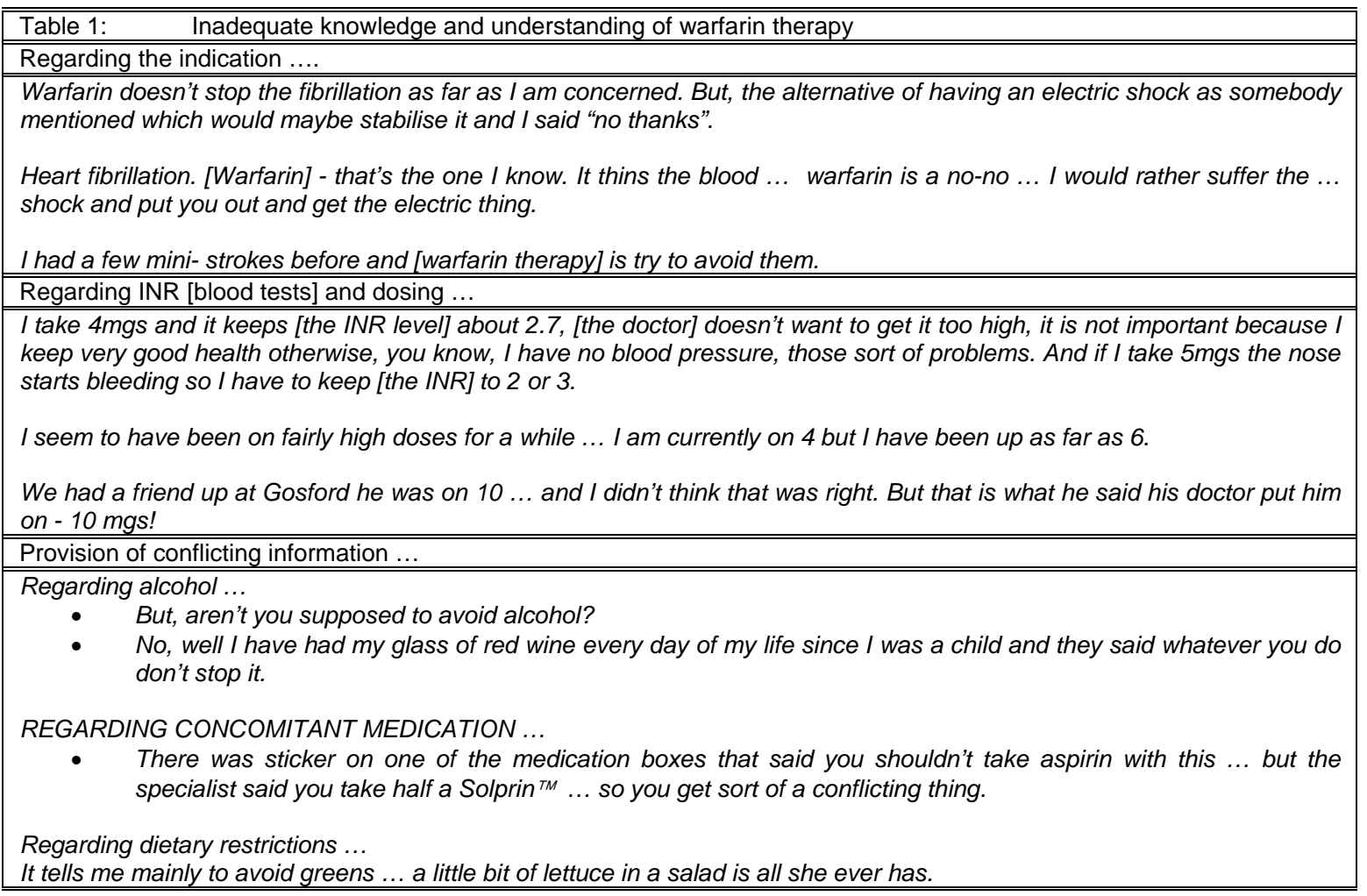

A similar deficit in knowledge and understanding was expressed on the practical aspects of warfarin use. Most participants accepted that blood (INR) testing was a necessary and routine part of the therapy, however, they did not understand how it related to the risk of either bleeding or stroke. Although they broadly understood that the INR was somehow an indicator of the necessary warfarin dose the vast majority believed that high doses were reserved for 'sicker' patients and were a marker of poorer health, a concept applied to most other medications (but not relevant to warfarin).

It became apparent that some of these misunderstandings originated from the conflicting advice received from either their peers (i.e., other patients, carers) or health professionals. Issues such as alcohol intake, diet, and concomitant use of other medication (especially aspirin), were most prone to being misconstrued. Participants firmly, but falsely, believed that they had to adhere to strict dietary restrictions, without reference to vitamin $\mathrm{K}$ intake or its relationship to the INR.

Despite some obvious misunderstandings, it was clear that participants knew more about warfarin than any other concomitant medication that they were taking. On the subject of warfarin, they were able to give comprehensive accounts of their treatment regimens and particular recording systems.
Theme 2: Patients experience of information provision

Whilst the quality of verbal information initially received by consumers varied across practice settings, written information was uniformly satisfactory and reliant on the use of the 'little blue book' (Anticoagulant Therapy booklet, Boots Pharmaceuticals, manufacturers of Coumadin ${ }^{\mathrm{TM}}$ ), particularly for dietary advice. Consumers depended heavily on the booklet, which served both as a source of information and as a practical tool for managing their therapy (Table 2). Obtaining this booklet proved a challenge for some participants who, on the advice of their practitioners, tried to unsuccessfully obtain the booklet from the community pharmacist. For those who were initiated on warfarin in the community setting, provision of the booklet (when it occurred) was not followed by substantial or useful verbal information from the community pharmacist.

Those who commenced therapy in the hospital setting and who were counselled by the hospital pharmacist were generally satisfied with the verbal information received, however that provided by the prescribing clinician was variable in content and quality. Satisfaction levels were greater when information was provided in an atmosphere of individualised and focused care, giving consumers 
the opportunity to process and understand it. A personal approach was extremely important in terms of ongoing support and the patient's confidence in warfarin therapy (Table 2).

Table 2: Patients experience of information provision

Regarding written information ...

Each time he goes in he gets the same book.

I have to work with this all the time, every night, put in the reading, put in my dosage. I am juggling it around a bit and it is very hard to remember all the things, so I enter it in pencil. I do it as soon as I have left the doctor and as I take them I ink in the figure of the dosage and then he also has a record. I don't have to tell him, I just give it to him and it makes life a lot easier.

The specialist didn't give me this [book] ... he said that you could get this book and I had to go to two pharmacists to get one ...I think it could be better communication ... they just gave me the book.

Regarding education in the hospital...

The pharmacist came around and explained it all to me in every detail and gave me a book of what I should eat and what I shouldn't eat

There was a team of about five doctors ... all around the bed and they all talked to me.

No criticism of the doctors but not much explanation just a sort of a wry comment, that they use it for rat poison, it was not very reassuring.

I didn't get anything ... only very sketchy in [hospital]... I haven't received anything extra at all

Regarding education in the community ...

[The chemist] did explain ... not to take it with aspirin and things like that ... just take it with water.

I go to a big pharmacy in Chatswood and you hand the script over and there are about six pharmacists all rushing around like mad things behind the counter ... You've got about five people lining up to get served ... there is a big sign ... 'Talk to your pharmacist' ... I don't know that that is working all that well ... there is a need for some sort of central place.

The doctor ... looked it up on the computer and he said, "deadly, don't take any more [tramadol]"... and yet I had asked the pharmacist ... she said well there is nothing on our computer other than to just watch for any black spots you have come up on you ... I have got to go back from him and feed her the information that she wasn't aware of.

I was disappointed that there wasn't much being done, just a label was just being sent off ... I see my GP but he doesn't seem to offer much advice or anything.

Table 3: Patients' expressed needs for information

Personally prefer that I read the book first and then come back and say 'I am not sure about this or that, could you explain this to me'.

I found it very difficult to sit on the other side of [the cardiologist's] desk and try and make notes of what he was saying. Now to him... it is a routine thing that he says ... for me it is the first time I heard this ... I don't think it should be left verbally ... [and the doctor] follows this up with again verbal advice.

I could have done with a bit more [information] ... another microgram or milligram or whatever it is ... I just don't know what is too much or too little and I am not clear on INR. I wouldn't mind knowing a bit about that because I am the one who is taking it. That is not a criticism, just a plea for more background.

I did have lots of information, as much as I needed, but when I got home, and practised I found... [that] every two weeks I would give blood and it would alter. I just wondered, what is the good of it? ...I must have warfarin and they were saying to prevent stroke ... just want to be sure that I am doing the right thing so I won't get a stroke.

There is a diabetes educator ... who fills me in [on diabetes management] and gives me all the reasoning and good motivation to keep at it ... I wouldn't mind there being ... a warfarin blood thinning educator ... that you could phone or go to ....because if I've got any doubts like that I might stop it entirely.

The local doctor is great for prescribing the next amount to take according to the INR ... but I just feel that I am a bit alone, it is a bit of a journey travelling solo. Well either the limitations of time to do that or even the limitation of expertise I think ... So really the scope is something to be set up, educating bureau or forum or something.

There was an expressed need for more information, with verbal and written forms of information being equally important to patients (Table 3 ). However, a single counselling session and/or the simple supply of a booklet was insufficient education for most. Some felt that they needed more background information about warfarin, such as an explanation of the reasons for taking warfarin, how it worked, how dose adjustments were made, and observed phenomena (e.g., bruising, variable INR results). They needed this to solidify their understanding of the therapy and therefore their confidence in using it, given that it had major impacts on their daily life. Neither verbal counselling experiences nor the booklet adequately catered to this need. Many expressed that the information needed to be provided in a paced manner with the opportunity of verifying their understanding at a later time. Further, 
they preferred that it should come from the health professionals who were most involved in their care.

Those who received apparently satisfactory and comprehensive education stated that despite this, they found it difficult to apply the knowledge once in their home setting, particularly when there was no reinforcement. The need for ongoing support and resources was again paramount for this group of consumers. Face-to-face accessible support services were necessary. Most felt that the GP was not able to offer this sort support, due to time restrictions, consequently some consumers felt quite solitary in their warfarin management. Although few of these consumers had actively sought the support and advice of community pharmacists regarding warfarin therapy, they were generally disheartened about the quality and current level services available. They expressed that pharmacists did not always have up-to-date information, particularly regarding drug interactions. Participants were not only dissatisfied by the lack of precautionary information about drug interactions and adverse effects generally, but also that what they did receive from the community pharmacist was sometimes retrospective.

Theme 3: Patients' reactions to being on warfarin

Consumers progressed through a 'cycle of reactions' regarding warfarin use, describing fear, followed by acceptance, and then dependence (Table 4). Initial fear and anxiety was largely directed at the practical aspects of therapy rather than any risk of bleeding or adverse events.

\section{Table 4: Consumer reactions to being on warfarin}

On initial reactions...

Shock, horror. Yes ... when you hear of friends who go onto warfarin ... blood testing that is needed to control the warfarin properly ... that was my first reaction, oh dear oh dear there is another medical procedure which we are forced to follow. It is not like taking a Panadol TM ... certainly you learn to live with it.

My reaction was that I couldn't eat broccoli and the things I loved, spinach and all those things.

I didn't have any other sort of reaction. I just accepted it as I had the pacemaker and they told me I was going to be wonderful, which was very true ... didn't worry me at all.

I was pleased because this was part of the recovery for me ... I have never had any worries about taking it On current attitudes toward warfarin ....

I'm just not worried about it. Things are going along smoothly and it goes up and down a bit but it doesn't seem to be affecting me, it doesn't interfere with my life at all.

Happy to take it ... if that can avoid the chances of strokes and things ... little inconvenience to take it ... As far as going to pathology on a regular basis, in the early stage it was a big nuisance but you get to know all the girls down at the pathology and ... (laughter) it was an enjoyable visit every time... I walk around with a smile on my face.

I didn't care less, it is just another tablet to take. The only thing that annoys me a bit ... warfarin doesn't stop the fibrillation as far as I am concerned.

I didn't take it for six weeks ... [then] I had a stroke ... I've been on it ever since. I wouldn't have a clue if the INR [blood test result] was up or down ... doesn't worry me ... just change the dosage.

Concerns about day-to-day issues...

It is all this nonsense, in the garden. Doctor says wear long sleeved shirt and I get too hot to wear a long sleeved shirt so I just cope with the black spots that come up and the bleeding ... I just put the hose on it and just go ahead.

I often wonder if you did have a fall and the ambulance came and you were bleeding what extra measures the ambulance would take ... obviously if you are on [warfarin] the bleeding will be a bit harder to stop.

I get a little bit upset when I ring the doctor and ... [the blood] is a bit thick at the moment ... now what am I not eating, or eating or drinking and not drinking that could better the situation ... it would be help if I could get some info.

They just say that there may be a reaction to antibiotics, you know just watch out for it, but it is very hard to watch out for something when you don't know whether it is going to cause this or that or the other thing.

Warfarin-naive consumers were less fearful than those who had been exposed to stories or myths about its use. Following appropriate education, fear quickly turned into acceptance of the therapy, particularly if warfarin was commenced after a significant clinical event or intervention. After a period of time in which participants were able to establish a routine and get accustomed to the therapy, they became somewhat dependent on it. They were generally quite accepting of the therapy, in spite of the fact that some participants (who were misguided about its indication) considered it to be ineffective. Those who had previously suffered a stroke were dependent on it, whilst those who were taking it for primary prevention were more sceptical about its use.

Whilst the majority accepted the doctor's decision and complied with the therapy, not everyone was entirely enthusiastic about warfarin; one participant in particular was fairly antagonistic towards it, albeit for reasons other than the risks of warfarin, and constantly raised arguments against its use whilst in desperate search of security and reassurance regarding it. 
I am very, very anti-warfarin ... it is not the warfarin, but you cannot take [naproxen] ... I suffer from rheumatoid arthritis and you cannot take warfarin in conjunction ... sotalol ... it doesn't have side effects ... it has got no 'no-nos'. With warfarin ... you can't have other things with it, whereas sotalol you can ... I am terrified of it.

In terms of ongoing concerns, day-to-day issues were more important to participants than monitoring issues or adverse effects. Most participants were curious rather than fearful about what might happen if a serious bleed occurred. Those who reported episodes of bleeding regarded them to be no more than a 'nuisance'.

Many expressed that it was difficult to maintain a stable INR and this was reflected in frequent dose changing. Although INR fluctuations occurred frequently, were annoying and often unexplainable, most participants appeared to accept subsequent dose changes as a matter of course. All had a good recollection of these dose changes. Some consumers were bothered by the inability to account for the altering INR readings, in spite of their best efforts to follow the 'protocol' and to watch dietary intake of their 'greens'. Insecurity about dietary issues and the concomitant use of other medications persisted even after extended periods of treatment.

Theme 4: Self-management of warfarin therapy

Although most participants were quite happy to hand over the management of concomitant medication to an external party or carer, they were very much in complete control of their warfarin (Table 5). Many attached a special significance to it, developing routines or systems that essentially provided them with a coping strategy for this. What the routine entailed was not important, as each participant described their own individualised method, but rather that it was an intimately understood process that empowered them to confidently manage their warfarin.

Table 5: Management of warfarin

On managing warfarin versus other medications

Carer: "She takes seven different pills every morning but one day a week she takes an extra one. Now I couldn't tell you what they are all for ... I have a very efficient pharmacist and she keeps the prescriptions ... gives me a list of what we need ... we have a little pillbox with all the days on it and every Wednesday I take that up and she fills it up".

Yet, on warfarin: -

"Actually I am a rather routine person ... about all these things and warfarin ... I have made out a program".

Patient: "Yes. [ramipril] and [metoprolol]. I have been taking [them] before warfarin ... [ramipril], yes, ... what is that for? Fibrillation. I don't know. I really don't know what I am taking it for. Except the warfarin."

This same consumer on her warfarin: -

"It is interesting to go back into the old [record book]. I was on 7.5mgs for a long, long time ... the last three times I have been 2.5 and I have been taking 3.5 so it is a bit different ... if I get a virus or infection it always starts off my asthma and then of course I am on the antibiotics and the prednisone and then my INR goes up and down".

On self-developed management strategies ...

I take mine at 7 o'clock every night. I find that is convenient. We live in the hostel and dinner at night is 6 o'clock, so 7 o'clock is a good time when I come back and before I sit down at the TV.

I take mine going to bed which is normally 10.30 or 11 o'clock ... you get into a pattern and you don't forget.

On blood-testing routines ....

I go to a pathology service in Chatswood ... [the doctor] gets the result... I ring him the next day and say what is the INR and then we discuss what I should be doing.

I just go to the local doctor ... takes the blood himself and sends it up to pathology ... I ring him back at 5 o'clock and he says stay as you are or change it around. I have no problem taking it, it is just a routine.

We started off having blood taken once a week, that went on from the start until $9^{\text {th }}$ August, then ... went on for some time fortnightly. Then it seemed to steady and we have been having it every four weeks ... it kept very nicely between 2 and 3 from the $6^{\text {th }}$ September until the $9^{\text {th }}$ January, it edged up a little like 2.3, 2.8, 2.6, 2.8 and then it got to 3.1 ... So after the 3.1 in the next four weeks it dropped to 2 and so, the pathologist calls and I ring the doctor the next day and they tell me what it is.

We tripped around a bit but wherever I was if I was due for an INR I would go to the local pathologist with a letter I was given by my doctor ...I would get the reading from them and if it was consistent ... I just continued on the same dosage... That worked all right.

All participants were able to describe exactly how they incorporated set routines into their daily lives to manage their warfarin and their rationale for this regimen. Likewise, each participant had an established routine for their blood testing.
Maintaining a good relationship with the doctor and pathology service was important to participants for their ongoing monitoring. For this reason, some were happy to sacrifice their holidays, or organise them around INR tests, so as to not interfere with 
their well-established and satisfactory testing processes. Others were undeterred by this prospect.

\section{Theme 5: Spectrum of experiences with warfarin}

Participants generally reported few problems with warfarin use (Table 6). Some consumers reported serious episodes of bleeding and considered them to be nothing more than annoyances and detrimental only in terms of cosmetic effects. A few were more concerned that they weren't bleeding as much as anticipated.

Overall, this consumer group felt that they had little to suggest in the way of strategies to assist warfarin use and prevent bleeding, given their satisfactory management and few adverse experiences. Several suggested placing an emphasis on mechanisms that alerted others to the fact that they were on warfarin, as in the case of emergencies.

Table 6: Spectrum of experiences with warfarin

On bleeding episodes

I have been taking it for five years and I just don't have any [problems], other than I bleed more freely, I have no reaction to it at all. Except for that I wouldn't know I was taking it.

One day you're going on perfect and the next day, [bruises] all over me, not from bumping or anything.

Easy bruising yes. It is very ugly, but you know, just put up with it.

Oh, my wife finds blood all over my clothes when I am out in the garden but still that's the only inconvenience and sometimes you have got to rush in and get a Band-Aid ${ }^{T M}$ whereas normally you would put up with it and let it bleed but other than that, not a problem.

What does it mean when it doesn't bleed at all? You have a cut and hardly a little line of blood where the cut is ... I have been waiting for this avalanche of blood.

On other adverse effects

Sometimes I get a bit clammy, but it may not be the warfarin it could be other things like the [aspirin].

I have also got nausea. That might be ... I can't blame warfarin for it ... I have fruit juice in the morning and I blame that ... but I cut it out but I still got nausea. But that's not fair for warfarin.

On suggestions to minimise risks of warfarin therapy ...

Get yourself a bracelet ... "I take anticoagulants" ... a little more stress could be put on the wearing of these things. Whether people like it or not ... from an ambulance person's point of view or a doctor's, it is handy to know this because if you are unconscious.

I carry a letter in my handbag wherever I go, my full history and what medications I am on.

\section{DISCUSSION}

Although previous studies have explored the perspectives of prescribers ${ }^{18-20}$, none have probed further to identify the experiences and perceptions of elderly patients and their carers regarding warfarin therapy, despite the reluctance of clinicians to prescribe warfarin for elderly patients due to perceived patient refusal. ${ }^{7-10}$ This is the first known study to have examined in-depth the perspectives of elderly patients and/or their carers in this local clinical setting.

Overall, the results of this study refute the notion that elderly patients are likely to refuse warfarin therapy. Although its use was an emotive clinical process for these participants, the initial fear and anxiety was quickly transformed into acceptance, and then dependence, following appropriate education and an adjustment period (i.e., time to establish a management plan and routine). Those who were commenced on warfarin after a significant clinical event or intervention (biological factor) were most accepting of the therapy. A fear of excessive bleeding was not expressed as a deterrent to its use. Even in those who had experienced some bleeding, minor episodes were perceived to be more of a cosmetic nuisance, whilst more serious bleeds were simply accepted as part of the therapy. Of course, these findings pertain to patients who have been able to continue warfarin therapy for a period of time (i.e., demonstrated tolerability), and who had not yet experienced a major adverse clinical event requiring therapy to be stopped.

Regarding the practicalities of the therapy, for the most part patients were not deterred by the processed involved. Although keeping track of blood testing, dosage adjustments, and 'dietary restrictions' was cumbersome they did not regard these to be major impositions upon them. Despite clinicians' concerns about patients' ability to cope with these aspects of warfarin, participants in this study did not feel incapable of managing their therapy. In fact, they appeared to do so more effectively than for other concomitant medication, treating warfarin differently and with more respect than other medication. Special emphasis was placed on warfarin and, in acknowledgement of the regimen's complexity, participants relied on selfdeveloped routines and independent copingmechanisms to assist them. This contrasts with health professionals' perceptions of non-compliance with warfarin in the elderly. ${ }^{7-10}$

What concerned participants most about warfarin therapy was the lack of detailed information to support them in the processes (dietary changes, blood testing) that they were required to follow whilst using warfarin, e.g., accurate information about dietary restrictions, the interpretation of blood test results. Undertaking these activities was physically not a problem, however the lack of understanding as to why these things were 
necessary, and to what extent, created some uncertainties and lead them to seek reassurance: participants expressed a need for reassurance from all of those involved in their treatment, particularly the general practitioner. Unequivocally, the general practitioner was central to both the practical and emotional components of warfarin management, and therefore the avoidance of problems associated with its use. It was expressed that the difficulties with warfarin came from the limited accessibility of both the treating general practitioner and other services for ongoing support, advice, education, and reassurance. For this reason, they felt somewhat abandoned in their management of warfarin, and were left with no option other than to assume a great deal of personal responsibility for their therapy. Self-developed strategies for their independent management of warfarin were therefore necessary.

The level of attention paid to warfarin is somewhat surprising, given that several of the participants did not fully understand its purpose. This is important in view of previous research that has identified that patients are more likely to be non-compliant with warfarin when they do not know why it has been prescribed, and/or perceive fewer benefits for an increased burden. ${ }^{21}$ Indeed, in this current study, those who were most accepting of warfarin were those who understood and appreciated its clinical importance. Patient knowledge underpins patient preferences, and is integral to treatment compliance, and this is particularly important for decision-making regarding anticoagulant therapy. Other studies highlight this, reporting that patientperceived thresholds of benefit for choosing anticoagulation vary widely and do not always coincide with those in clinician-generated guidelines, in accordance with the amount of information imparted to them. ${ }^{11,12,22}$

Overall, these findings are consistent with other surveys suggesting that patients' decision-making is primarily driven by the fear of stroke and death, and less so by the inconvenience, minor side effects and costs of warfarin. ${ }^{22}$ In terms of the bio-psycho-social factors, in the elderly the focus appears to be on the psychological factors affecting warfarin use (uncertainty regarding the purpose of the therapy, the meaning of blood test results, fear of making errors in management due to lack of information), rather than the biological (physical processes of blood testing, episodes of bleeding) or social factors (lifestyle changes, limitations to daily activities). This is contrary to clinicians' current perceptions, and highlights that patients are quite amenable to the therapy, despite any residual anxiety being driven by a lack of knowledge. Other studies examining biopsychosocial influences on regimen adherence, for example in type 1 diabetes, have also shown that psychosocial factors, such as education and positive coping styles, account for more variance in clinical outcomes (e.g., glycaemic control) than biological factors. ${ }^{23}$

Collectively, what all of these findings highlight is the importance of education in helping patients appreciate that the benefits of warfarin outweigh the costs (risk of bleed, stringent care, monitoring), which then influence the acceptability of, preferences for, and compliance with therapy. Previous studies have also identified that insufficient information is provided to patients about therapeutic options, particularly elderly patients commenced on long-term therapy for chronic conditions such as heart disease, asthma, diabetes, arthritis, and stroke. ${ }^{24}$ This prevents their active involvement in the therapy and/or participation in decision-making processes. ${ }^{25}$ The results of this study support that patients who are armed with knowledge, are more accommodating of the therapy in the long-run than those who have a limited understanding of the risk and benefit of the therapy and/or the additional processes involved. Knowledge about the risks and benefits of therapy may be partly acquired through experiencing the outcome (e.g., stroke), however, for a preventative therapy acquisition of knowledge in this manner is both inappropriate and ineffective. Patients may also acquire information via illinformed third parties (e.g., peers and relatives) ${ }^{26}$, and the dangers of relying on this is highlighted by the fact that warfarin-naive participants in this study were less fearful than those who had been exposed to stories or myths about its use. There is an identified need for health care professionals to offer more education to these patients; the current reliance of health carers on the communication of information via the provision of a single 'information booklet' and/or isolated verbal counselling sessions is insufficient. This "lack of systematic and continuous education" has also been identified for young patients with chronic illness. ${ }^{27}$ It should be recognised that, across all age groups, "people's appetite for information about their treatment is often greater than doctors believe". ${ }^{26-28}$ Greater effort is needed to not only educate patients about the risks and benefits of treatment, but also to provide ongoing services that incorporate follow-up care, access to information, and the necessary reassurance for patients over the long-term. Such an ongoing service should also allow for the exchange of information between health professionals and patients, including feedback from patients to prescribers about their treatment preferences. ${ }^{29}$ Studies are currently underway to develop and evaluate appropriate educational material for the target elderly population, as well as community-based services that incorporate the education and counselling of warfarinised patients. Although hospital-based anticoagulation clinics are a mainstay of care in many countries, their accessibility to older patients is somewhat restricted (i.e., functional impairments may impede travel to clinics), hence the need to develop local, community-based services that may outreach to atrisk older patients.

In interpreting the findings of this study it is important to acknowledge that the perspectives raised here by the participants may not necessarily be generalisable to all warfarinised patients. Indeed, these participants represent patients requiring longterm therapy who have had (on average) a few years to adapt to their treatment regimen and therefore may have been more positive in their appraisal of warfarin. Additionally, because 
participation was voluntary, our sample may represent those who had particular viewpoints that they wished to express, whether positive or negative (e.g., grievances). However, careful facilitation of the group discussions yielded a diverse range of perspectives, both positive and negative, as described in the results. Due to the restricted sample size and the small number of carers, it was not possible to fully elucidate any specific differences in perspectives between patients and carers, although as a whole, the perspectives of both patient/carer groups were essentially similar.

\section{CONCLUSIONS}

Elderly patients and their carers appear to be quite accepting of warfarin therapy, in contrast to the perceptions of health care professionals. More effort is needed, however, in terms of information provision, particularly in the form of communitybased services, to assist patients in the long-term management of warfarin.

\section{ACKNOWLEDGMENTS}

A grateful thank-you is extended to Dr Peter Veitch and Dr Alex Bune (Staff Specialists, Royal North Shore Hospital, NSW, Australia) for their involvement in, and support of, this study.

\section{CONFLICT OF INTEREST}

The authors have no conflicts of interest to declare. This project was funded by the Commonwealth Department of Health and Ageing (Australia), Quality Use of Medicines Evaluation Program.

\section{References}

1. Enis J. Stroke prevention in patients with non-valvular atrial fibrillation: a current community perspective. J Clin Neuroscience. 1997;4:320-325.

2. Ang S, Peterson G, Friesen W, Vial J. Review of antithrombotic drug usage in atrial fibrillation. J Clin Pharm Ther. 1998;23:97-106.

3. Stewart F, Singh $Y$, Persson S, Gamble G, Braatvedt G. Atrial fibrillation: prevalence and management in an acute general medical unit. Aust NZ J Med. 1999;29:51-58.

4. Elliott R, Woodward M, Oborne C. Appropriateness of antithrombotic prescribing for elderly inpatients with atrial fibrillation. Pharm J. 1999;263:R10.

5. Jackson S, Peterson G, Vial J, Daud R, Ang S. Outcomes in the management of atrial fibrillation: clinical trial results can apply in practice. Intern Med J. 2001;31:329-336.

6. Bajorek B, Krass I, Ogle S, Duguid M, Shenfield G. The impact of age on antithrombotic use in elderly patients with nonvalvular atrial fibrillation. Australas J Ageing. 2002;21:36-41.

7. Chang H, Bell J, Devoo D, Kirk J, Wasson J. Physician variation in anticoagulating patients with atrial fibrillation. Arch Intern Med. 1990;150:81-84.

8. Kutner M, Nixon G, Silverstone F. Physicians' attitudes toward oral anticoagulants and antiplatelet agents for stroke prevention in elderly patients with atrial fibrillation. Arch Intern Med. 1991;151:1950-1953.

9. McCrory D, Matchar D, Samsa G, Sanders L, Pritchett E. Physician attitudes about anticoagulation for nonvalvular atrial fibrillation in the elderly. Arch Intern Med. 1995;155(3):277-281.

10. Munschauer F, Priore R, Hens M, Castilone A. Thromboembolism prophylaxis in chronic atrial fibrillation: practice patterns in community and tertiary-care hospitals. Stroke. 1997;28:72-76.

11. Howitt A, Armstrong D. Implementing evidence based medicine in general practice: audit and qualitative study of antithrombotic treatment for atrial fibrillation. BMJ. 1999;318:1324-1327.

12. Gottlieb L, Salem-Schatz S. Anticoagulation in atrial fibrillation: does efficacy in clinical trials translate into effectiveness in practice? Arch Intern Med. 1994;154:1945-1953.

13. Morgan D, Kreuger R. When to use focus groups and why? In: Morgan D, editor. Successful focus groups. London: Sage; 1993

14. White $Y$, Grenyer B. The biopsychosocial impact of end-stage renal disease: the experience of dialysis patients and their partners. J Adv Nurs.1999;30:1312-1320.

15. Husserl E. Ideas: general introduction to pure phenomenology. Evanston, Illinois: Northwestern University Press; 1931.

16. Moustakas C. Phenomenological research methods. Thousand Oaks, California: Sage; 1994.

17. Kidd P, Parshall M. Getting the focus and the group: enhancing analytical rigor in focus group research. Qual Health Res. 2000;10:293-308.

18. McCrory D, Matchar D, Samsa G, Sanders L, Pritchett E. Physician attitudes about anticoagulation for nonvalvular atrial fibrillation in the elderly. Arch Intern Med. 1995;155:277-281.

19. Lip G, Zarifis J, Watson R, Beevers D. Physician variation in the management of patients with atrial fibrillation. Heart. 1996;75:200-205.

20. Peterson G, Boom K, Jackson S, Vial J. Doctors' beliefs on the use of antithrombotic therapy in atrial fibrillation: identifying barriers to stroke prevention. Intern Med J. 2002;32:15-23.

21. Arnsten J, Gelfand J, Singer D. Determinants of compliance with anticoagulation: a case-control study. Am J Med. 1997;103:11-17.

22. Man-Son-Hing M, Laupacis A, O'Connor A, Wells G. Warfarin for atrial fibrillation: the patient's perspective. Arch Intern Med. 1996;156:1841-1848. 
23. Peyrot M, McMurry J, Kruger D. A biopsychosocial model of glycemic control in diabetes: stress, coping and regimen adherence. J Health Soc Beh. 1999;40(2):141-158.

24. Barber N, Parsons J, Clifford S, Darracott R, Horne R. Patients' problems with new medication for chronic conditions. Qual Saf Health Care. 2004;13:172-175.

25. Coulter A, Entwistle V, Gilbert D. Sharing decisions with patients: is the information good enough? BMJ. 1999;318:318322.

26. Dickinson D, Raynor D, Kennedy J, Bonaccorso S, Sturchio J. What information do patients need about medicines? BMJ. 2003;327:861.

27. Kyngas H. Patient education: perspective of adolescents with a chronic disease. J Clin Nurs. 2003;12(5):744-751.

28. Berry D, Michas I, Gillie T, Forster M. What do patients want to know about their medicines and what do doctors want to tell them? A comparative study. Psychol Health. 1997;12:467-480.

29. Britten N, Stevenson F, Barry C, Barber N, Bradley C. Misunderstandings in prescribing decisions in general practice: qualitative study. BMJ. 2000;320:484-488.



For any inquiries, please use the following email address: 161 SPW@ff.ul.pt

Hope to have you here in Summer 2010! 